\title{
Pengujian fixed bed gasifier dengan bahan bakar biomassa
}

Mohammad Azis $\mathbf{M}^{\mathbf{1}}$

\author{
${ }^{1}$ Jurusan Teknik Mesin, Fakultas Teknologi Industri, ITENAS, Bandung
} Email korespondensi: m.azis.mahardika@gmail.com

\begin{abstract}
Abstrak
Saat ini, kebutuhan manusia akan energi semakin besar dan terus bertambah, dikarenakan jumlah penduduk yang semakin meningkat. Ketergantungan akan bahan bakar fossil dapat dilihat dari pemakaian energi di Indonesia, saat ini pemakaian energi didominasi oleh minyak bumi 46,9\%, gas alam 21,9\%, batubara 26,4\%, dan biofuel, panas bumi, EBT lainya 4.8\%. Oleh karena itu untuk mengurangi ketergantungan pada bahan bakar fosil ini dapat digunakan energi alternatif lain yang merupakan energi terbarukan seperti biomass. Selain itu diperlukan teknologi untuk meningkatkan efisiensi pembakaran maka diperlukan proses untuk mengkonversi bahan bakar padat menjadi bahan bakar gas yaitu proses gasifikasi. Pada penelitian ini, dilakukan pengujian reaktor gasifikasi tipe downdraft. Pada hasil pengujian ini didapatkan CGE (Cold Gas Efficency) sebesar 41,1\% dan kandungan gas hasil gasifikasi CO2 (2,98\%), H2 (2,66\%), N2 (66,99\%), CO (15,71\%), CH4 (2,98\%), H2S (0,15\%) dengan AFR sebesar 2,47.
\end{abstract}

Kata kunci: EBT,CGE, Gasifikasi, AFR,

\begin{abstract}
Currently, the human need for energy is growing larger, due to the increasing population. The dependence on fossil fuels can be seen from Indonesia's energy usage. Nowadays, energy consumption is dominated by petroleum (46.9\%), natural gas (21.9\%), coal (26.4\%), and other (4.8\%). Therefore, to reduce dependence on fossil fuels, biomass can be used as alternative energy which is renewable. In addition, technology required to improve the combustion efficiency is necessary. To convert solid fuel into gas fuel is gasification process. In this research, the downdraft gasification type reactor was tested. In this test, results obtained are CGE (Cold Gas Efficiency) by $41.1 \%$ and the gas content of CO2 (2.98\%), H2 (2.66\%), N2 (66.99\%), CO (15.71\%), CH4 (2.98\%), H2S (0.15\%) with an AFR of 2.47
\end{abstract}

Keywords: EBT,CGE, Gasifikasi, AFR

\section{Pendahuluan}

Saat ini, kebutuhan manusia akan energi semakin besar dan terus bertambah, dikarenakan jumlah penduduk yang semakin meningkat Energi dibutuhkan manusia untuk berbagai aspek dalam kehidupan seperti listrik, transportasi, perindustrian, dan berbagai kebutuhan rumah tangga. Untuk menghasilkan energi dibutuhkan sumber energi. Bahan bakar fosil seperti batubara, minyak, gas alam merupakan sumber energi tak terbarukan, Karena proses terbentuknya yang lama dan ketersediaanya yang semakin menipis maka bahan bakar fosil disebut sumber energi tak terbarukan. sedangkan biomassa, angin, panas matahari, panas bumi, dan lain-lain merupakan sumber energi terbarukan. Dikarenakan proses terbentuknya yang relatif cepat dan ketersediaanya yang sangat banyak. [1]

Ketergantungan akan bahan bakar fossil dapat dilihat dari pemakaian energi di Indonesia, saat ini pemakaian energi didominasi oleh minyak bumi $46,9 \%$, gas alam $21,9 \%$, batubara $26,4 \%$, dan biofuel, panas bumi, EBT lainya $4.8 \%$ [2]. Penggunaan bahan bakar fossil dapat menyebabkan masalah ekonomi, sosial, dan lingkungan. Masalah utama pemakaian bahan bakar fosil adalah persediaan bahan bakar fossil yang semakin menipis menyebabkan harganya yang semakin mahal. Oleh karena itu untuk mengurangi ketergantungan pada bahan bakar fosil ini dapat digunakan energi alternatif lain yang merupakan energi terbarukan seperti biomass Biomass berasal dari hasil pertanian, perkebunan, dan limbah hutan. Indonesia merupakan penghasil biomass yang cukup besar sehingga sayang jika tidak digunakan salah satu contohnya adalah kayu. Tetapi walaupun biomass mempunyai biomass yang melimpah tetapi terdapat masalah pada penggunaan biomassa yaitu polusi yang dihasilkan. Oleh karena itu untuk mengurangi polusi dapat menggunakan teknologi gasifikasi.

Gasifikasi merupakan proses konversi bahan bakar padat menjadi bahan bakar gas, dalam kata lain mengkonversi untuk bahan bakar biomass dapat dikonversi menjadi bahan bakar gas yang biasa disebut synthetic gas atau syngas [3]. Karena proses pembakarn gas yang lebih baik maka gas yang dihasilkan setelah pembakaran menjadi lebih bersih jika dibandingkan dengan pembakaran bahan bakar padat. Teknologi gasifikasi ini sudah diaplikasikan dalam pembangkit listrik yang dinamakan IGCC ( Integrated Gasification Combined Cycle ) 
Selain itu, Bahan bakar gas memiliki keunggulan yaitu proses distribusi yang lebih mudah dibandingkan dengan mendistribusikan bahan bakar padat (khusus igcc), selain itu bahan bakar hasil gasifikasi ini juga ramah lingkungan, jika dibandingkan dengan pembakaran langsung biomass.

Selain itu, teknologi gasifikasi ini dapat diaplikasikan untuk energi alternatif di daerah yang tidak terjangkau transmisi listrik PLN, untuk kapasitas kecil teknologi ini dapat menghasilkan daya sebesar $100 \mathrm{KW}$.

\section{Metode}

\section{Diagram Alir}

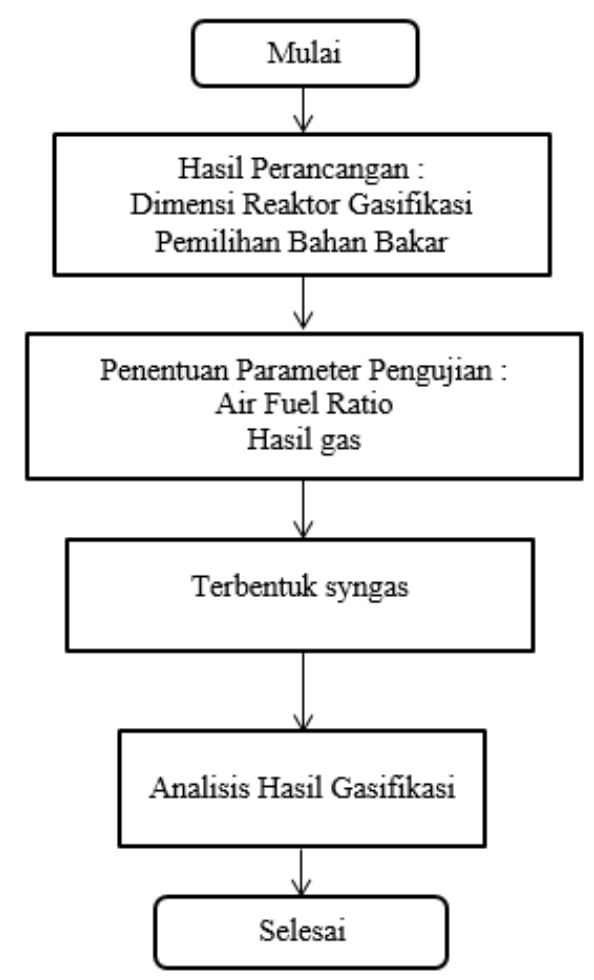

Gambar 1. Diagram alir proses pengujian

Diagram alir pada gambar 2.1 menunjukan diagram alir proses pengujian gasifikasi. Proses dalam penelitian ini diawali dengan memperoleh data-data hasil perancangan gasifikasi seperti dimensi reaktor, jenis reaktor gasifikasi, dan bahan bakar yang digunakan. Proses perancangan tidak akan dibahas pada penelitian ini. Berikut gambar 3 dimensi hasil perancangan reaktor gasifikasi yang ditunjukkan pada gambar 2.

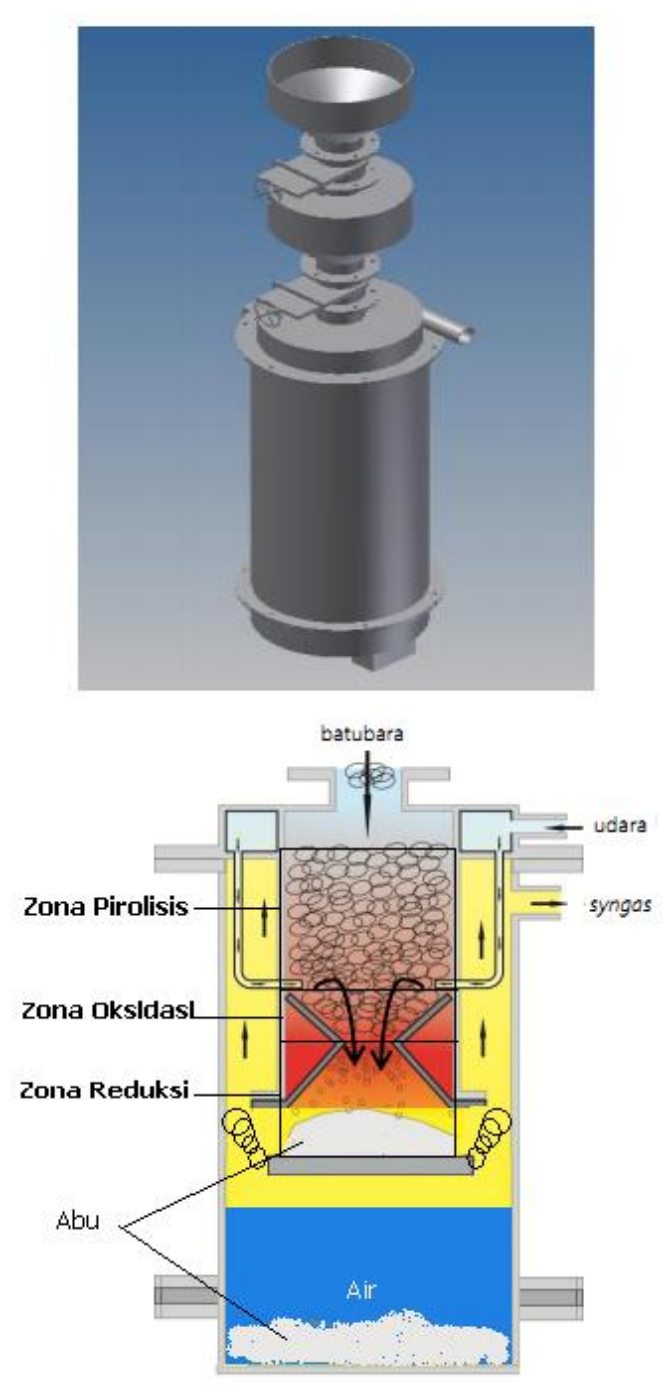

Gambar 2. Hasil perancangan reaktor gasifikasi [4]

Proses gasifikasi dibagi menjadi 3. Proses pirolisis terjadi pada zona pirolisis. Proses oksidasi terjadi pada zona oksidasi. Proses reduksi terjadi pada zona reduksi. Berikut dimensi yang diperoleh dari hasil perancangan

\section{Tabel 1. Dimensi Reaktor Gasifikasi}

\begin{tabular}{ll}
\hline Diameter throat $\left(\mathrm{d}_{\mathrm{t}}\right)$ & $100 \mathrm{~mm}$ \\
Diameter reaktor $\left(\mathrm{d}_{\mathrm{f}}\right):$ & $280 \mathrm{~mm}$ \\
Diameter zona pembakaran pada nosel $\left(\mathrm{d}_{\mathrm{n}}\right):$ & $220 \mathrm{~mm}$ \\
Tinggi nosel terhadap throat $(\mathrm{h}):$ & $110 \mathrm{~mm}$ \\
Jumlah nosel $(\mathrm{n})$ dan diameter nosel $\left(\mathrm{d}_{\mathrm{m}}\right):$ & $\mathrm{n}=5 \mathrm{buah}, \mathrm{d}_{\mathrm{m}}=11 \mathrm{~mm}$ \\
Kecepatan udara masuk $\left(\mathrm{u}_{\mathrm{m}}\right):$ & $26 \mathrm{~m} / \mathrm{s}$ \\
Tinggi zona pirolisis : & $300 \mathrm{~mm}$ \\
Tinggi zona reduksi : & $355 \mathrm{~mm}$ \\
\hline
\end{tabular}

Selanjutnya, untuk menghasilkan gas gasifikasi yang bersih maka diperlukan komponen pembersih gas hasil gasifikasi. Siklon dan filter ditambahkan pada sistem yang ditujukan untuk mengurangi zat pengotor syngas seperi tar dan abu. Pengujian dilakukan 
dengan skema sebagai yang ditunjukkan pada gambar 3 .

Proses pengujian dilakukan seperti yang ditunjukkan pada skema. Udara dan bahan bakar bercampur pada reaktor dalam keadaan pembakaran miskin. Laju massa udara diukur dengan menggunakan venturimeter yang dipasang pada sisi masuk udara. Laju massa bahan bakar dilakukan dengan cara menghitung jumlah bahan bakar yang dimasukkan pada reaktor dengan waktu yang diperlukan untuk membakar seluruh bahan bakar pada reaktor. Selanjutnya, sampel gas hasil gasifikasi diambil sebelum gas memasuki siklon, sampel diambil setelah gas hasil gasifikasi terbentuk dan sudah terbakar stabil pada burner.

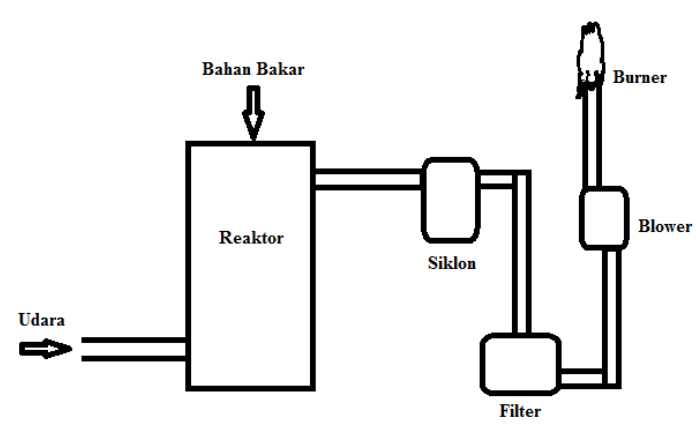

Gambar 3. Skema pengujian reaktor gasifikasi.

Hasil gas gasifikasi selanjutnya akan memasuki siklon yang berguna untuk memisahkan partikel-partikel pengotor pada gas dengan menggunakan prinsip gaya sentrifugal. Selanjutnya, gas hasil gasifikasi akan memasuki filter yang berisi dengan sekam jagung, hal ini bertujuan agar pengotor seperti tar atau uap air terserap sehingga hasil gas gasifikasi telah memiliki kualitas yang bagus. Blower digunakan untuk mengalirkan udara dan burner digunakan untuk mengetahui apakah gas hasil gasifikasi sudah terbentuk atau belum. Gambar 4 menunjukan alat pengujian gasifikasi yang sudah jadi.

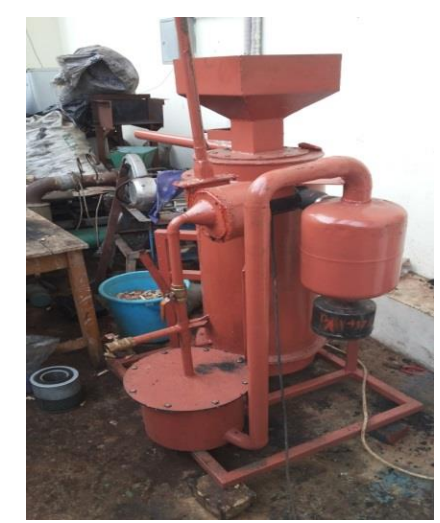

Gambar 4. Reaktor gasifikasi dan komponen pengujian

Selain itu, Pemodelan dilakukan untuk membandingkan hasil pengujian dan hasil dari pemodelan, pemodelan dilakukan dengan cycle tempo 5.0. berikut adalah pemodelan gasifikasi. pemodelan dilakukan dengan menggunakan 1 buah gasifier (4.3) 43 dan 5 buah apparatus (berbentuk lingkaran) seperti pada Gambar 5. Apparatus 1 adalah gasifier dengan temperatur reaksi sebesar $750{ }^{\circ} \mathrm{C}$, apparatus 2 adalah input biomassa yang memiliki temperatur 25 dengan tekanan 1 bar dan apparatus 3 sebagai input oksidan yang memiliki temperatur 25 dengan tekanan 1 bar. Apparatus 4 dan 5 berfungsi sebagai pendingin.

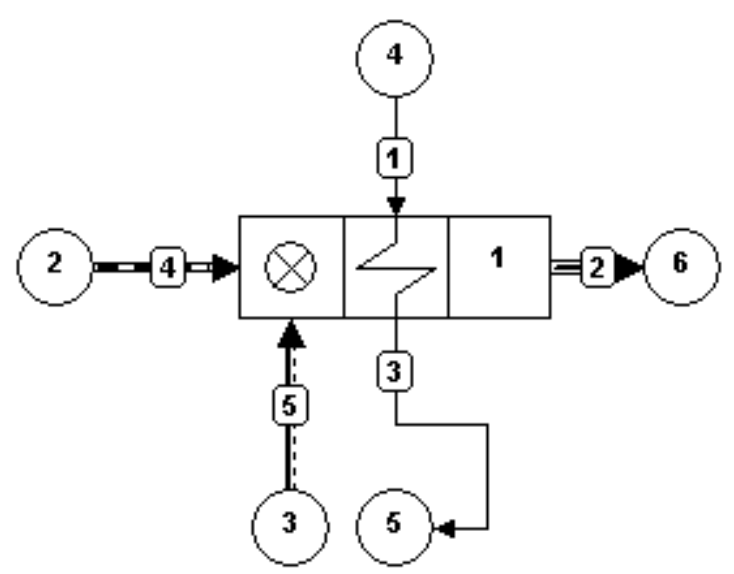

Gambar 5. Model gasifikasi

\section{Hasil dan Pembahasan}

Data-data hasil pengujian didapat dari pengambilan data sebelum dan sesudah pengujian berlangsung. Berikut adalah data hasil pengujian reaktor gasifikasi yang ditunjukkan pada Tabel 2. Pengujian dilakukan dengan menggunakan bahan bakar yang mudah didapatkan, yaitu kayu. Jumlah bahan bakar yang digunakan untuk pengujian sebesar $2 \mathrm{~kg}$, bahan bakar juga memiliki nilai LHV sebesar $26.400 \mathrm{~kJ} / \mathrm{kg}$. Pengujian berlangsung selama 1 jam 11 menit. Untuk proses start-up gasifikasi dibutuhkan waktu sekitar 15 - 20 menit dari proses pemasukan bahan bakar sampai burner menyala. Untuk mendapatkan api yang stabil maka perlu diatur laju massa syngas dengan mengatur inverter pada blower.

Tabel 2. Data pengujian reaktor gasifikasi

\begin{tabular}{|l|l|}
\hline Bahan Bakar & Kayu \\
\hline Massa Bahan Bakar & $2 \mathrm{~kg}$ \\
\hline LHV Bahan Bakar & $26.400 \mathrm{~kJ} / \mathrm{kg}$ \\
\hline Waktu Pembakaran & $1 \mathrm{jam} 11 \mathrm{menit}$ \\
\hline Temperatur Udara & $24^{\circ} \mathrm{C}$ \\
\hline Laju massa syngas & $0.00154 \mathrm{~kg} / \mathrm{s}$ \\
\hline AFR & 2,47 \\
\hline Kapasitas & $4,037 \mathrm{~kW}$ \\
\hline
\end{tabular}

Pada saat pengujian, setelah gas hasil gasifikasi sudah terbentuk, sampel gas diambil dan diuji kandungan gas dengan menggunakan gas kromatografi. Hasil dari uji gas yang dilakukan ditunjukkan pada Tabel 3 
. Gas hasil gasifikasi yang terbentuk adalah $\mathrm{CH} 4, \mathrm{CO}$, $\mathrm{H} 2$, dan H2S. Nilai LHV dapat dihitung dari komposisi gas yang terbentuk, maka didapatkan nilai LHV dari syngas sebesar $2622.7 \mathrm{~kJ} / \mathrm{kg}$.

Tabel 3. Fraksi volume kandungan syngas

\begin{tabular}{ccc} 
No & Gas & Fraksi Volume \\
\hline 1 & CO2 & $2.98 \%$ \\
2 & $\mathrm{H} 2$ & $2.66 \%$ \\
3 & $\mathrm{~N} 2$ & $66.99 \%$ \\
4 & $\mathrm{CO}$ & $15.71 \%$ \\
5 & $\mathrm{CH} 4$ & $2.98 \%$ \\
6 & $\mathrm{H} 2 \mathrm{~S}$ & $0.15 \%$
\end{tabular}

Pada hasil pemodelan gasifikasi komposisi hasil syngas gasifikasi. syngas yang diperoleh adalah gas CO sebesar 15,84\%, H2 15,36\%, dan $\mathrm{CH} 40.72 \%$ dengan LHV $3444.1 \mathrm{~kJ} / \mathrm{kg}$ dapat dilihat pada tabel 4

Tabel 4. Hasil pengujian dan pemodelan

\begin{tabular}{|l|r|}
\hline Hasil Pemodelan & 1 \\
\hline $\mathrm{C}(\mathrm{S})$ & 0.0000 \\
\hline $\mathrm{H} 2$ & 0.1193 \\
\hline $\mathrm{H} 2 \mathrm{O}$ & 0.0767 \\
\hline $\mathrm{N} 2$ & 0.5053 \\
\hline $\mathrm{AR}$ & 0.0060 \\
\hline $\mathrm{CO} 2$ & 0.1339 \\
\hline $\mathrm{CH} 4$ & 0.0001 \\
\hline $\mathrm{H} 2 \mathrm{~S}$ & 0.0004 \\
\hline $\mathrm{CO}$ & 0.1583 \\
\hline Avg.molemass [kg/kmol] & 26.36 \\
\hline LHV [kJjinol] & 73.93 \\
\hline $\mathrm{HHV}$ [kJjinol] & 79.20 \\
\hline
\end{tabular}

\begin{tabular}{|l|r|}
\hline Hasil Pengujian & 1 \\
\hline $\mathrm{CH} 4$ & 0.0298 \\
\hline $\mathrm{CO}$ & 0.1571 \\
\hline $\mathrm{CO} 2$ & 0.1151 \\
\hline $\mathrm{H} 2$ & 0.0266 \\
\hline $\mathrm{H} 2 \mathrm{~S}$ & 0.0015 \\
\hline $\mathrm{N} 2$ & 0.6699 \\
\hline Avg molemass [kg/kmol] & 28.81 \\
\hline LHV [kJ/hnol] & 75.56 \\
\hline HHV [kJ/inol] & 79.42 \\
\hline
\end{tabular}

Perbedaan yang cukup jauh terdapat pada kandungan $\mathrm{CH} 4$ dan $\mathrm{H} 2$, pada hasil pengujian menghasilkan jumlah yang lebih sedikit daripada hasil pemodelan, hal ini mungkin dikarenakan tidak tercapainya temperatur reaksi dari gasifikasi, dari hasil permodelan pengaruh temperatur reaksi pada proses gasifikasi sangat berpengaruh dalam pembentukan syngas, semakin kecil temperatur reaksi maka semakin kecil pula hasil gas yang dihasilkan. Tidak sampainya temperatur reaksi dikarenakan banyak panas yang terbuang keluar dari dalam reaktor. Selain itu juga tidak terjadi steam methane reforming reaction yang mengubah $\mathrm{CH} 4$ menjadi $\mathrm{H} 2$ dan $\mathrm{CO}$.

Parameter prestasi gasifikasi dapat dihitung melalui Cold Gas Efficiency dengan rumus sebagai berikut

Cold gas efficiency $=\frac{L H V_{\text {syngas }} \times \dot{m}_{\text {syngas }}}{L H V_{\text {bahan bakar }} \times \dot{m}_{\text {bahan bakar }}} \times 100 \%$

Diperoleh CGE (Cold Gas Efficiency) untuk pengujian hasil gasifikasi sebesar $41,1 \%$. Nilai ini merepresentasikan seberapa besar efisiensi nilai energi syngas jika dibandingkan dengan nilai energi bahan bakar asalnya, atau seberapa besar energi syngas yang didapat dari energi bahan bakar mula. Nilai CGE masih dapat ditingkatkan dengan menggunakan isolator panas pada dinding-dinding reaktor.
Serbuk kayu yang berada di dalam filter setelah pengujian menghitam seperti yang terlihat pada Gambar 5 menghitam, hal ini dikarenakan terdapat tar pada filter yang seharusnya tar terkondensasi dan terpisah pada siklon, tetapi siklon hanya mengkondensasi dan memisah sebagian tar. Dalam hal ini siklon yang dibuat kurang optimal. Pada Gambar 5 terlihat tar yang terbentuk pada siklon. Tar yang terbentuk pada reaktor gasifikasi dapat menjadi masalah, tar dapat menyumbat pipa dan juga blower, selain itu jika digunakan pada genset, tar dapat menempel pada dinding ruang bakar dan dapat merusak piston.

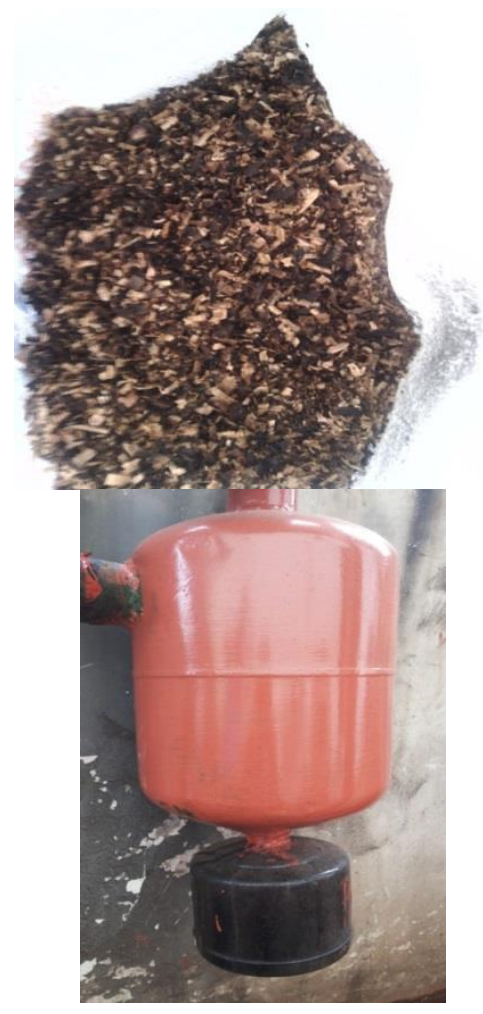

Gambar 5. Kondisi siklon dan filter setelah pengujian

\section{Kesimpulan}

Kapasitas reaktor yang diperoleh dari hasil pengujian sebesar 4,037 kW. Terdapat perbedaan kandungan gas hasil pengujian dan pemodelan, yang mungkin dikarenakan tidak tercapainya temperatur reaksi pada saat pengujian akibat banyaknya panas yang terbuang. Dengan LHV gas hasil pengujian sebesar $2622.7 \mathrm{kj} / \mathrm{kg}$ dan LHV gas hasil pemodelan sebesar $2840 \mathrm{kj} / \mathrm{kg}$. Perbedaan kandungan gas hasil pengujian dan pemodelan paling besar terjadi pada komposisi gas $\mathrm{CO}$ dan H2. Reaktor gasifikasi memiliki CGE sebesar 41.1\% dengan AFR sebesar 2.47.

\section{Daftar Pustaka}

[1] T.B. Reed dan A. Das, Handbook of Biomass Downdraft Gasifier Engine Systems, SERI, Washington DC, 1988. 
[2] Peraturan Presiden Nomor 5 Tahun 2006 Tentang Kebijakan Energi Nasional.

[3] C. Higman dan M. van der Burgt, Gasification, Gulf Professional Publishing, Oxford, 2008.

[4] A. Paramaputra, Perancangan Reaktor Gasifikasi Tipe Downdraft dengan Bahan Bakar Batubara, Teknik Mesin FTMD ITB, 2013. 